Revista da Sociedade Brasileira de Medicina Tropical

Journal of the Brazilian Society of Tropical Medicine

Vol.:52:e20190065: 2019

doi: 10.1590/0037-8682-0065-2019

\title{
Letter
}

\section{West Nile virus retinitis in a patient with neuroinvasive disease}

\author{
Suzana Konjevoda ${ }^{[1],[2]}$, Boris Dzelalija ${ }^{[3]}$, Samir Canovic ${ }^{[1]}$, Zrinjka Pastar ${ }^{[2]}$, \\ Vladimir Savic ${ }^{[4]}$, Irena Tabain ${ }^{[5]}$, Ljubo Barbic ${ }^{[6]}$, Ljiljana Peric ${ }^{[7],[8]}$, Dario Sabadi[7],[8], \\ Vladimir Stevanovic ${ }^{[6]}$ and Tatjana Vilibic-Cavlek ${ }^{[5],[9]}$
}

\author{
[1]. Department of Ophthalmology, General Hospital Zadar, Zadar, Croatia. \\ [2]. Department of Health, University of Zadar, Zadar, Croatia. \\ [3]. Department of Infectious Diseases, General Hospital Zadar, Zadar, Croatia. \\ [4]. Poultry Center, Croatian Veterinary Institute, Zagreb, Croatia. \\ [5]. Department of Virology, Croatian Institute of Public Health, Zagreb, Croatia. \\ [6]. Department of Microbiology and Infectious Diseases with Clinic, Faculty of Veterinary Medicine, University of Zagreb, Zagreb, Croatia. \\ [7]. Department of Infectious Diseases, Clinical Hospital Center Osijek, Osijek, Croatia. \\ [8]. Medical Faculty, Josip Juraj Strossmayer University of Osijek, Osijek, Croatia. \\ [9]. School of Medicine, University of Zagreb, Zagreb, Croatia.
}

\section{Dear Editor:}

The West Nile virus (WNV) is a widely distributed emerging mosquito-borne arbovirus. Although the majority of WNV infections are asymptomatic $(80 \%)$, some infected individuals $(20 \%)$ present with non-specific febrile disease (WNV fever) and less than $1 \%$ develop neuroinvasive diseases (meningitis, encephalitis, and myelitis). Several atypical or rare presentations of WNV infection such as cerebellitis, myocarditis, hepatitis, pancreatitis, and rhabdomyolysis have been described in case reports or small case series ${ }^{1}$. Although rare, ocular manifestations, including monofocal or multifocal WNV chorioretinitis are the most commonly reported clinical manifestations of WNV infection after fever and neuroinvasive disease $^{2-5}$.

We herein report the first case of retinitis detected in a patient with WNV neuroinvasive disease in Croatia. In August 2018, a 68 -year-old patient with type II diabetes mellitus was admitted to the infectious disease department with a six-day history of fever (temperature up to $38.9^{\circ} \mathrm{C}$ ), shivering, chills, vertigo, frontal headache, and fatigue. The patient came on holiday in a touristic area on the Adriatic Coast from the continental part

Corresponding author: Dr Tatjana Vilibic-Cavlek.

e-mail: tatjana.vilibic-cavlek@hzjz.hr

Orcid: 0000-0002-1877-5547

Received 4 March 2019

Accepted 16 April 2019 of Croatia where autochthonous WNV infections have already been registered continuously from $2012^{6,7}$, as well as in the 2018 transmission season (unpublished data of the Reference Centre for Diagnosis and Surveillance of Viral Zoonoses, Croatian Ministry of Health, Croatian Institute of Public Health). In the coastal area, autochthonous human WNV infections had not been detected so far. According to the epidemiological history (arbovirus transmission season, living in the area with documented arbovirus circulation, and reported mosquito bites), an arboviral etiology was suspected.

On physical examination, the patient was confused, restless with slight tremors of the hands, and had conjunctival hyperemia. On the lower extremities, there were multiple mosquito bites. Routine blood laboratory parameters were within normal ranges except for an elevated glucose level $(9.0 \mathrm{mmol} / \mathrm{L}$, reference range 4.4-6.4 mmol/L). Cerebrospinal fluid analysis showed pleocytosis $\left(437 \times 10^{6} / \mathrm{L}\right.$ cells) with lymphocyte predominance $(67 \%)$, elevated protein level $(1.40 \mathrm{~g} / \mathrm{L}$; reference range $0.17-0.37 \mathrm{~g} / \mathrm{L})$, and elevated glucose level $(5.7 \mathrm{mmol} / \mathrm{L}$, reference range $2.5-3.3 \mathrm{mmol} / \mathrm{L}$ ). An electroencephalogram showed nonspecific changes while a brain computed tomography scan showed normal findings.

On the 9th day after disease onset, he developed sudden decreased visual acuity in both eyes. Ophthalmologic examination revealed conjunctival injection, while other parts of the anterior segment of the eye were unremarkable. The visual acuity in both eyes was classified using the semiquantitative scale of "hand motion". Intraocular pressure was normal. In the 
posterior segment of the eye, vasculitis, edema, and hemorrhage of the entire retina were found (Figure 1). Fluorescent angiography showed bilateral occlusion of the retinal blood vessels with centrally located ischemic areas.

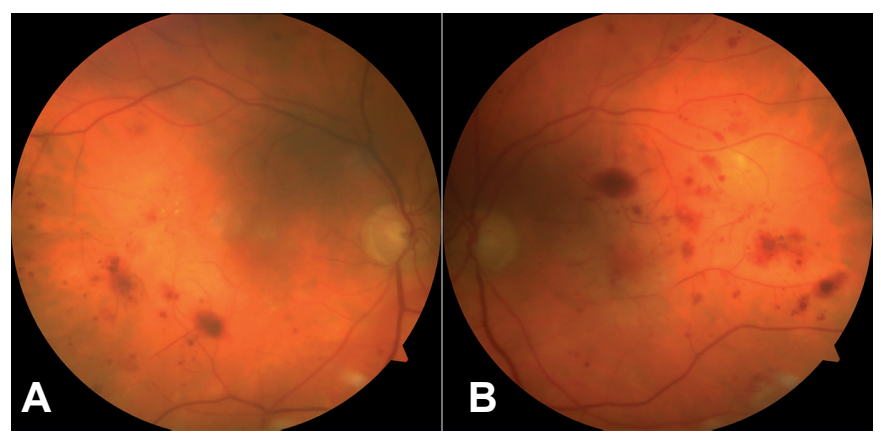

FIGURE 1: Fundus photograph of the right (A) and left (B) eye shows retinitis with preretinal and intraretinal hemorrhages.

Repeated blood cultures showed negative results. Serological tests were performed using commercial enzyme-linked immunosorbent assays (Euroimmun, Lübeck, Germany). The diagnosis of WNV neuroinvasive disease was confirmed by seroconversion in samples obtained during the acute and convalescent phases. In the first sample tested on day 8, positive IgM antibody assay results (ratio $1.25 ;>1.1$ positive) were found while $\mathrm{IgG}$ antibody assay results were negative (10.58 $\mathrm{RU} / \mathrm{ml} ;>22$ positive). In the second sample tested on day 27 , both $\operatorname{IgM}$ (ratio 1.48) and $\operatorname{IgG}(142.10 \mathrm{RU} / \mathrm{ml})$ antibodies were found. IgG antibodies showed low avidity $(24 \%$; $<40 \%$ low avidity index) indicating acute WNV infection. To rule out cross-reactivity with other flaviviruses, serology for tick-borne encephalitis virus and Usutu virus was also performed. Antibody assay results for both tick-borne encephalitis virus and WNV were negative. Additionally, WNV infection was confirmed by detection of WNV RNA in the first serum sample using a realtime reverse transcriptase-polymerase chain reaction according to the protocol of Tang et al. ${ }^{8}$ Real-time reverse transcriptasepolymerase chain reaction for Usutu virus showed negative results according to the protocol of Nikolay et al. ${ }^{9}$ Herpes simplex virus DNA was not detectable in cerebrospinal fluid by quantitative polymerase chain reaction.

Based on the clinical symptoms and virological results, acute WNV meningoencephalitis and retinitis were diagnosed. The patient was initially treated with acyclovir, ampicillin, and ceftriaxone with supportive therapy (antiedematous and antiaggregation therapy). On control examination after one month the patient still reported blurred vision with complete resolution of meningitic symptoms. A control electroencephalogram yielded normal findings.

Ophthalmic presentations in arboviral infections in general are not common ${ }^{10}$. Intraocular involvement during WNV infection was first described in 2003. Ocular manifestations can be present at the time of fever or may manifest after many weeks. Anterior uveitis, optic neuritis, and retinitis are the most common manifestations during the acute infection ${ }^{11}$. In Croatia, ocular involvement in patients with WNV infection has not been documented so far. WNV chorioretinitis tends to occur in older patients, those with coexisting diabetes mellitus, with higher likelihood of presenting with encephalitis like the patient presented in this report ${ }^{12}$. However, some studies reported retinitis also in younger, nondiabetic patients ${ }^{3}$. The exact pathogenesis of the ocular manifestations associated with WNV is not known; however, it has been speculated that hematogenous dissemination of virus to the choroidal circulation may result in chorioretinitis or chorioiditis ${ }^{2}$.

In conclusion, the case presented in this report highlights the need for awareness of the possibility of WNV-related retinitis during the arbovirus transmission season. In addition, routine ophthalmological examination should be considered, especially in patients presenting with severe WNV encephalitis.

\section{Financial Support}

This study was supported in part by the Croatian Science Foundation, projectno. IP2016-06-7456: "Prevalence and Molecular Epidemiology of Emerging and Re-emerging Neuroinvasive Arboviral Infections in Croatia"; CRONEUROARBO (to Tatjana Vilibic-Cavlek). The Ethics Committee of the Croatian Institute of Public Health approved the study.

\section{Conflict of interest}

The authors declare that there is no conflict of interest.

\section{REFERENCES}

1. Sejvar JJ. Clinical manifestations and outcomes of West Nile virus infection. Viruses. 2014;6(2):606-23.

2. Vandenbelt S, Shaikh S, Capone A Jr, Williams GA. Multifocal choroiditis associated with West Nile virus encephalitis. Retina. 2003;23(1):97-9.

3. Sivakumar RR, Prajna L, Arya LK, Muraly P, Shukla J, Saxena D, et al. Molecular diagnosis and ocular imaging of West Nile Virus retinitis and neuroretinitis. Ophthalmology. 2013;120(9):1820-6.

4. Learned D, Nudleman E, Robinson J, Chang E, Stec L, Faia LJ, et al. Multimodal imaging of West Nile virus chorioretinitis. Retina. 2014;34(11):2269-74.

5. Merle H, Donnio A, Jean-Charles A, Guyomarch J, Hage R, Najioullah F, et al. Ocular manifestations of emerging arboviruses: Dengue fever, Chikungunya, Zika virus, West Nile virus, and yellow fever. J Fr Ophtalmol. 2018;41(6):e235-e243.

6. Pem-Novosel I, Vilibic-Cavlek T, Gjenero-Margan I, Pandak N, Peric L, Barbic L, et al. First outbreak of West Nile virus neuroinvasive disease in humans, Croatia, 2012. Vector Borne Zoonotic Dis. 2014;14(1):82-4.

7. Vilibic-Cavlek T, Kaic B, Barbic L, Pem-Novosel I, Slavic-Vrzic $\mathrm{V}$, Lesnikar V, et al. First evidence of simultaneous occurrence of West Nile virus and Usutu virus neuroinvasive disease in humans in Croatia during the 2013 outbreak. Infection. 2014;42(4):689-95.

8. Tang Y, Anne Hapip C, Liu B, Fang CT. Highly sensitive TaqMan RT-PCR assay for detection and quantification of both lineages of West Nile virus RNA. J Clin Virol. 2006;36(3):177-82. 
9. Nikolay B, Weidmann M, Dupressoir A, Faye O, Boye CS, Diallo $\mathrm{M}$, et al. Development of a Usutu virus specific real-time reverse transcription PCR assay based on sequenced strains from Africa and Europe. J Virol Methods. 2014;197:51-4.

10. de Andrade GC, Ventura CV, Mello Filho PA, Maia M, Vianello $\mathrm{S}$, Rodrigues EB. Arboviruses and the eye. Int J Retina Vitreous. 2017;3:4.
11. Lee JH, Agarwal A, Mahendradas P, Lee CS, Gupta V, Pavesio CE, et al. Viral posterior uveitis. Surv Ophthalmol. 2017;62(4):404-5.

12. Hasbun R, Garcia MN, Kellaway J, Baker L, Salazar L, Woods $\mathrm{SP}$, et al. West Nile Virus retinopathy and associations with long term neurological and neurocognitive sequelae. PLoS One. 2016;11(3):e0148898. 